\title{
Optimization of environmental maintenance system used in a refuge chamber
}

\author{
Junling Yang ${ }^{1} \cdot{\text { Luwei } \text { Yang }^{1} \cdot \text { Chong Zhang }}^{1} \cdot$ Zhentao Zhang $^{1,2} \cdot{\text { Xiaojiang } \mathrm{Li}^{3}}^{3}$
}

Received: 24 March 2015/Revised: 29 April 2015/Accepted: 28 July 2015/Published online: 14 November 2015

(C) The Author(s) 2015. This article is published with open access at Springerlink.com

\begin{abstract}
Mine refuge chambers are used to shield miners who fail to escape from the mine when incidents occur. Environment maintaining system plays a key role in stabilizing thermal environment of a mine refuge chamber against heat emitted from metabolism and transferred from outside. The safety and comfort of refugees are closely related to the environment maintaining system design. In order to improve the comfort of refugees, optimization on the environment maintaining system has been done based on the previous work. To evaluate the environment of the chamber, eight volunteers were involved into the experiment. Under close observation and safety protection, they lived in a heat-isolated test chamber for 106 hours. The volunteers were asked to maintain low level of activities to simulate refugees' situation. It shows that the environment maintaining system worked well and the temperature, relative humidity and emitted harmful air content such as $\mathrm{CO}_{2}$ and $\mathrm{CO}$ were all kept in the safety level, and no discomfort was felt by volunteers at all.
\end{abstract}

Keywords Environment maintaining system - Mine refuge chamber - Temperature - Relative humidity ·

$\mathrm{CO}_{2}$ concentration $\cdot \mathrm{CO}$ concentration

\section{Introduction}

Mine refuge chambers are used to shield miners who fail to escape from the mine when incidents occur. They should provide breathable air, food, water and a safe environment, which is essential to the refugees.

Mine refuge chamber would be heated and humid due to internal refugees and external underground situation. High levels of heat and humidity could cause sweating, paleness, cramps, tiredness, weakness, dizziness, headache, nausea or vomiting, and fainting. An environment maintaining

Luwei Yang

yangj1@mail.ipc.ac.cn

1 Technical Institute of Physics and Chemistry of CAS, Beijing 100190, China

2 Changzhou Boruijieneng Energy and Environment Corporation, Changzhou 213031, China

3 Xinjiang Coal Scientific Research Institute, Urumqi 830091, China system includes a refrigerator, a pressure balance system and an air cleaning subsystem. The refrigerator mentioned in previous work is used to control temperature and humidity in the chamber. The pressure balance system is used to keep the internal pressure in a reasonable range. The air cleaning subsystem, also located in the refrigerator, is used to absorb $\mathrm{CO}_{2}$ and $\mathrm{CO}$ in the air recycling (Yang and Yang 2013).

The temperature, relative humidity and the concentration of $\mathrm{CO}_{2}$ and $\mathrm{CO}$ are important factors that affect the comfort and safety of the refugees

There were a large number of studies about the thermal comfort in offices and work buildings. Memon assessed the thermal comfort within the classroom of a university in subtropical of Pakistan and found that more than $80 \%$ of people were satisfied at an effective temperature of $32.5^{\circ} \mathrm{C}$ (Memon et al. 2008). Sander ter Mors et al. investigated the thermal comfort and thermal comfort parameters for children in primary school classrooms. The questionnaires had been applied to obtain the actual thermal sensation and clothing insulation in the morning and afternoon of regular 
school days (Mors et al. 2011). Noh et al. studied thermal comfort and indoor air quality in lecture room (Noh et al. 2007). Muhi and Butala studied the influence of thermal environment and air quality level on the employees in the mechanical ventilated administrative offices (Muhi and Butala 2004). An examination of thermal comfort in a hospital had been conducted (Pourshaghaghy and Omidvari 2012). Abbritti et al. estimated the value of PMV in sick buildings (Abbritti et al. 1992). Sabrina et al. assessed indoor environment quality for hypermarket workers and found that data collected at fixed point locations showed only minor (and predictable) biases due to expectation and to transition through different thermal environments (Sabrina et al. 2012). Jan et al. made an evaluation of the optimal temperature in each cabin of the Korean maritime patrol vessels and found that the optimum temperature was $23{ }^{\circ} \mathrm{C}$ in the wheelhouse and $29{ }^{\circ} \mathrm{C}$ in the accommodation (Jan et al. 2007).

All the papers mentioned above focused on the environment of the ordinary buildings. The mine refuge chamber is narrow in space and works in incidents situation. In result of these features, internal environment condition and air quality would be different from previous studies. Jia et al. investigated the refrigerating characteristics of ice melting enclosed in a cube capsule in coal mine refuge chamber (Jia et al. 2015). Jia et al. studied on purification characteristic of $\mathrm{CO}_{2}$ and $\mathrm{CO}$ within closed environment of coal mine refuge chamber by mean of the simulation device (Jia et al. 2014). In this paper, the performance of the environment maintaining system is examined.

\section{Experiment description}

In the experiment, a full-size heat isolated chamber was built, and eight volunteers lived in the chamber for 106 hours under close observation and safety protection. Their age ranges from 18 to 35 , and they had the same wearing. During the experiment, they could only consume food and water prepared in the chamber and the door of the chamber was kept closed. If any discomfort was felt or the volunteers were in danger, the door could be opened from both inside and outside. The volunteers had breakfast regularly at 8:00 am, lunch at 12:00 am and supper at 5:00 pm. In most of duration, they were asked to maintain low level of activities. It is shown in Fig. 1 that the volunteers were sitting in the chamber.

Figure 2 is the photo of the refrigerator and air cleaning subsystem. Figure $2 a$ is the previous one and Fig. $2 b$ is the present design. The present one is a compacter design and the air flow distributes more non-uniformly. The refrigerators are open cycle because the compressor should not be used in a coal

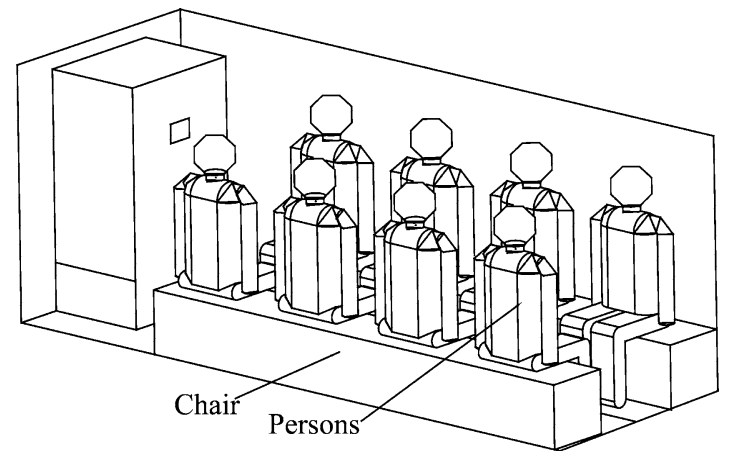

Fig. 1 Persons sitting in the chamber

mine. On the one hand, in most situations the electric power supply breakdown will occur at an accident, and the refrigerator will fail to run. On the other hand, the compressor is located outside of the refuge chamber, and could be damaged by gas explosions that often occur in underground coal mines (Fang et al. 2012; Zhao and Qian 2012; Zhao et al. 2012).

Both of the refrigerators include four rooms. The air outlet is aligned differently in position to the four rooms. Once the air in the chamber goes into the cabinet, it will travel in such a sequence: Firstly, air with ambient temperature is inhaled into the cabinet at the bottom, and then goes through the condensed water room. After reducing humidity air goes through the $\mathrm{CO}_{2}$ absorption room and the $\mathrm{CO}$ absorption room in sequence, where $\mathrm{CO}_{2}$ and $\mathrm{CO}$ is absorbed. Then, the air goes through evaporator and is cooled down as a result. Finally, low temperature and breathable air is blown out from the cabinet into the chamber.

The personnel activity was observed by a camera in real time, and the experiment data of temperature, relative humidity, $\mathrm{CO}_{2}$ concentration and $\mathrm{CO}$ concentration in the chamber were recorded by the computer.

Three thermometers $\left(\operatorname{Tr}_{1}, \mathrm{Tr}_{2}\right.$ and $\left.\mathrm{Tr}_{3}\right)$ were arranged in the chamber evenly in heights, see Fig. 3. The relative humidity sensors, $\mathrm{CO}_{2}$ concentration sensors, $\mathrm{CO}$ concentration sensors, $\mathrm{O}_{2}$ concentration sensors and gauge pressure sensors were at the same location of the three thermometers. The dates were recorded every $30 \mathrm{~min}$. The dates in the follow figs were measured values by the sensors.

All the sensors used in the experiment were calibrated. The temperature was measured by pt100 thermometers with an accuracy of $\pm 0.1{ }^{\circ} \mathrm{C}$, and the corresponding relative humidity is measured by JWSK-6 with accuracy of $\pm 0.5{ }^{\circ} \mathrm{C}\left(-20\right.$ to $\left.60{ }^{\circ} \mathrm{C}\right), \pm 3 \% \mathrm{RH}(5 \% R H-95 \% R H)$ made by a corporation named Collihigh in China. The pressure in the experiment is measured by MEAS pressure sensors calibrated with a standard pressure source with accuracy of $\pm 0.25 \%$ BSL, $\max$ (combined linearity, hysteresis \& repeatability). The $\mathrm{CO}$ concentration, $\mathrm{CO}_{2}$ concentration and $\mathrm{O}_{2}$ concentration were measured by sensors with accuracy of $\pm 2 \%, \pm 0.1 \%$ and $\pm 3 \%$, respectively. 


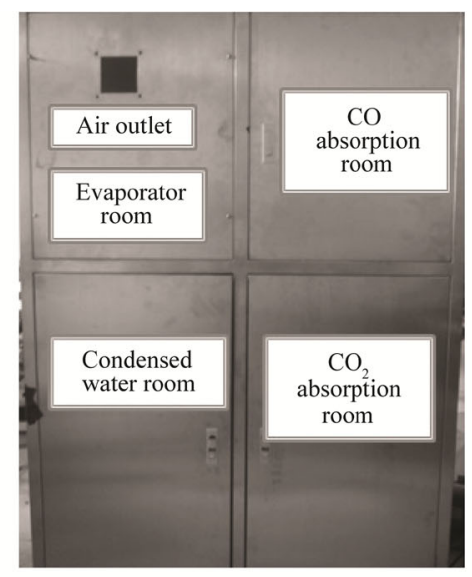

(a)
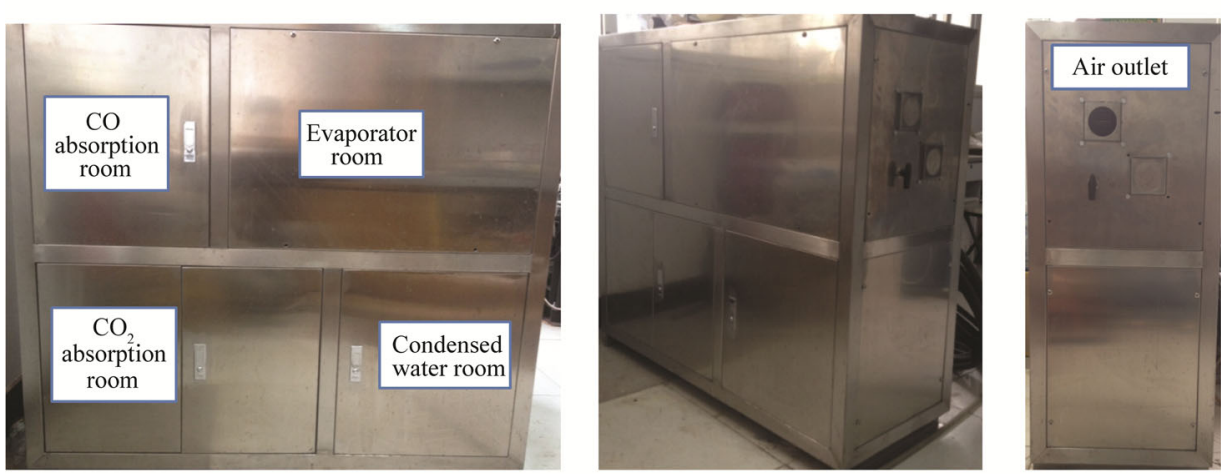

(b)

Fig. 2 Refrigerator and air cleaning subsystem. a The previous, b the present

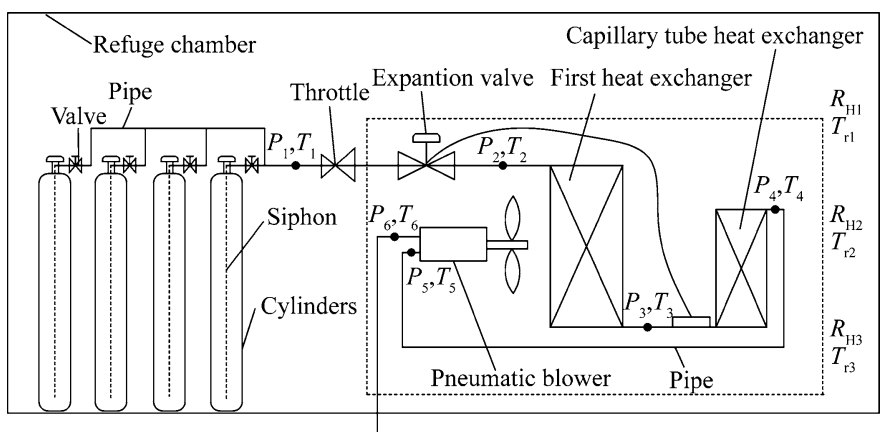

Fig. 3 Arrangement of the sensors

\section{Experimental results and discussions}

\subsection{Temperature and relative humidity in the chamber}

Figures 4 and 5 are the temperature and relative humidity in the chamber. Internal temperature increased sharply after volunteers' entering. The heat from volunteers' metastasis warmed internal air up to $30{ }^{\circ} \mathrm{C}$. Because they were in exciting or anxious mood, depending on their different psychological status, the amount of diffused heat was very large at this stage. After they calmed down gradually, the temperature decreased to an ordinary level and varied via time. Normally, the temperature ranged between 25 and $28{ }^{\circ} \mathrm{C}$ and the relative humidity ranged between $50 \%$ and $70 \%$. When they had dinner, the temperature would increase to the maximum of $30{ }^{\circ} \mathrm{C}$, while the relative humidity increases to $75 \%$. On contract, the temperature would drop down to the minimum of $23{ }^{\circ} \mathrm{C}$ with a relative humidity of $45 \%$ when they were sleeping. It is shown that level of personnel's activity impact internal temperature and relative humidity greatly in such a narrow 


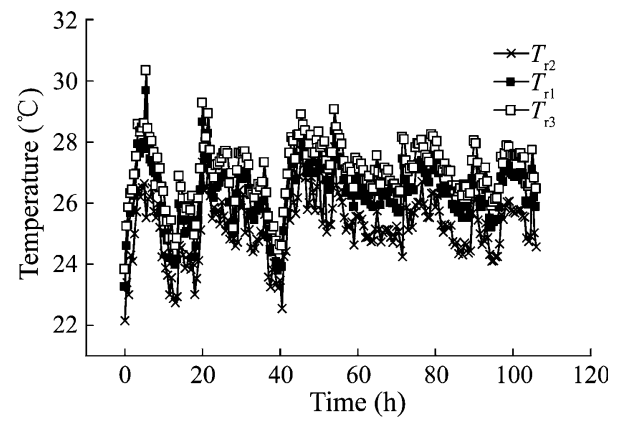

Fig. 4 Temperature varies with time in the chamber

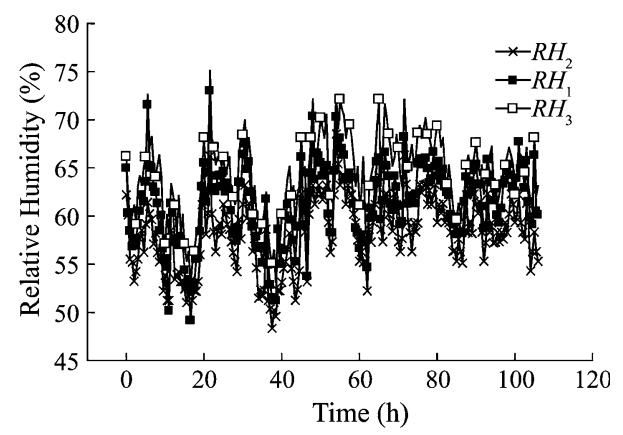

Fig. 5 Relative humidity varies with time in the chamber

space. Position of $\operatorname{Tr}_{2}$ was located towards the cold air flow, which resulted a low reading than $\operatorname{Tr}_{1}$ and $\operatorname{Tr}_{3}$.

\section{2 $\mathrm{CO}_{2}$ and $\mathrm{O}_{2}$ concentration in the chamber}

The concentration of $\mathrm{CO}_{2}$ and $\mathrm{O}_{2}$ are $1 \%$ and $21 \%$ respectively in atmosphere. Regarding the complex situation in the refuge chamber, the concentration might change, but should stay in breathable level. So the extra $\mathrm{CO}_{2}$ should be absorbed by the air cleaning system. Figure 6 illustrates the $\mathrm{CO}_{2}$ concentration in the $106 \mathrm{~h}$. The concentration varied between $0.2 \%$ and $0.7 \%$ and remained stable, nearly $0.5 \%$, most of the time. This means the absorption capability is enough for 8 personnel. In this result, it also could be seen that the concentration was lower in the middle than the other two positions due to a better convection situation.

The $\mathrm{O}_{2}$ is supplied by the $\mathrm{O}_{2}$ cylinders placed in the chamber before the experiment. The flow rate of the $\mathrm{O}_{2}$ is controlled by a throttle. Figure 7 is the concentration of $\mathrm{O}_{2}$ in the chamber. It ranged from $19.5 \%$ to $22 \%$. From the data above, it could be seen that the air in the closed chamber has almost the same content as the atmosphere, which ensures the personnel's safety.

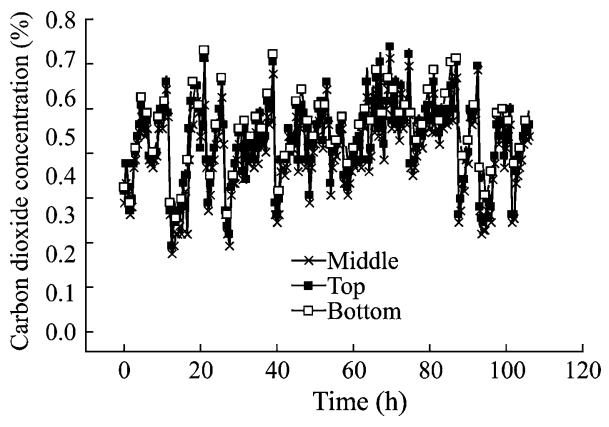

Fig. $6 \mathrm{CO}_{2}$ concentration varies with time in the chamber

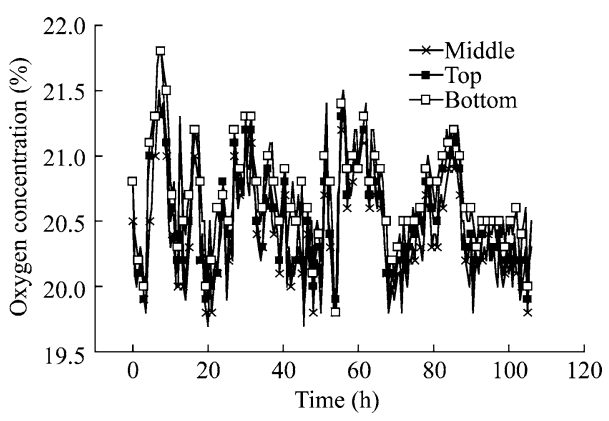

Fig. $7 \mathrm{O}_{2}$ concentration varies with time in the chamber

\subsection{Pressure in the chamber}

Tinnitus, chest distress and poor breath might happen when persons are living in an environment with too high or too low pressure. The pressure balance system is designed to maintain a suitable pressure in the chamber by supplying and relieving air when the pressure is below $-200 \mathrm{~Pa}$ and over $600 \mathrm{~Pa}$. Figure 8 shows the gauge pressure in the chamber. It could be seen that the gauge pressure varied round $300 \mathrm{~Pa}$ in the range of $150-450 \mathrm{~Pa}$. The sensors at the three positions had almost the same reading. Due to this pressure balance system, no discomfort was felt during the experiment.

\subsection{CO concentration in the chamber}

High concentration of $\mathrm{CO}$ might lead to $\mathrm{CO}$ poisoning. $\mathrm{CO}$ is rarely produced in human's metabolism, in case of incidental accumulation, $\mathrm{CO}$ absorbing function is designed to active automatically according to $\mathrm{CO}$ concentration. Figure 9 is the $\mathrm{CO}$ concentration during the experiment. The concentration of the $\mathrm{CO}$ was zero in the first $30 \mathrm{~h}$ and $\mathrm{CO}$ absorbing function was off. When small amounts of $\mathrm{CO}$ was produced by metabolism and accumulated up to $4 \times 10^{-6} \mathrm{~g} / \mathrm{mL}$ at maximum, the $\mathrm{CO}$ absorbing function was triggered on automatically. After 


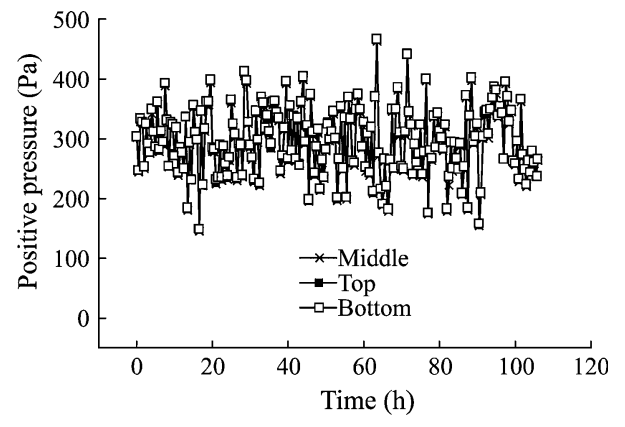

Fig. 8 Gauge pressure varies with time in the chamber

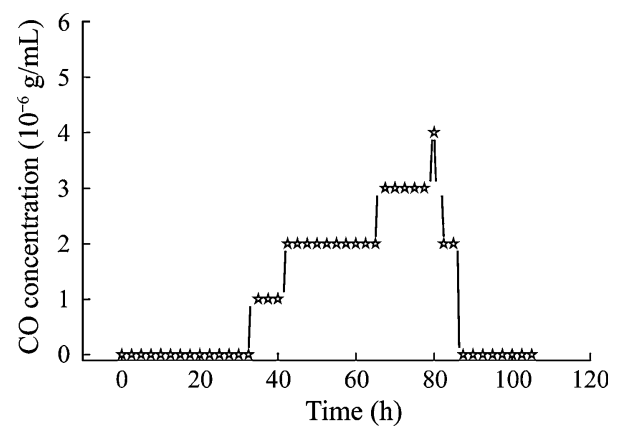

Fig. $9 \mathrm{CO}$ concentration varies with time in the chamber

$30 \mathrm{~min}, \mathrm{CO}$ concentration reduced. During this period the volunteers did not feel uncomfortable at all.

In summary, the environment maintaining system functions as follow: air in the chamber is inhaled into the cabinet, the pollution in the air is absorbed and the air is cleaned and cooled down in the refrigerator, then cool and fresh air is blown out. The environment maintaining system provides a fundamental environment for human's living. According to the experiment above, all the functionality of the system ran well and no discomfort was felt in the duration of 106 hours. This means the system has the capability to provide a good environment for life maintenance in case of incidents. To improve personnel's comfort, the flow around the human body would be further analyzed.

\section{Conclusions}

The environment maintaining system was optimized and tested when eight volunteers living in. The experiment results showed the conclusions as follow:

(1) The system could control the temperature between 25 and $28{ }^{\circ} \mathrm{C}$ and the relative humidity was between $50 \%$ and $70 \%$, which were the comfortable range for human being.

(2) The $\mathrm{CO}_{2}$ concentration varied between $0.2 \%$ and $0.7 \%$ and stayed nearly $0.5 \%$, which was the same as the air content and was safe.
(3) The $\mathrm{O}_{2}$ concentration ranged from $19.5 \%$ to $22 \%$ and was suitable for breathing.

(4) The gauge pressure was controlled in the range of 150 to $450 \mathrm{~Pa}$.

All the parameters were within the safety range, and no discomfort was felt. This meant the optimizing of the environmental maintaining system was reasonable and was useful for the design of the chamber.

Acknowledgments This research was supported by the Natural Science Foundation of Jiangsu Province (BK20140274); the Director Foundation of Institute of Physics and Chemistry, CAS (2014-yjl) and Xinjiang "125" Major Projects (201130112).

Open Access This article is distributed under the terms of the Creative Commons Attribution 4.0 International License (http://creative commons.org/licenses/by/4.0/), which permits unrestricted use, distribution, and reproduction in any medium, provided you give appropriate credit to the original author(s) and the source, provide a link to the Creative Commons license, and indicate if changes were made.

\section{References}

Abbritti G, Muzi G, Accattoli MP, Fiordi T, Dell'Omoa M, Colangelia C, Gabriellia AR, Fabbria T, D'Alessandro A (1992) High prevalence of sick building syndrome in a new air conditional building in Italy. Arch Environ Health 47(1):16-22

Fang HF, Ge SR, Cai LH, Hu EY (2012) Buckling analysis of the shell of a refuge chamber in a coal mine under uniform axial compression. Int J Min Sci Technol 22(1):85-88

Jan MS, Koh CD, Moon IS (2007) Review of thermal comfort design based on PMV/PPD in cabins of Korean maritime patrol vessels. Build Environ 42(1):55-61

Jia YX, Liu YS, Liu WH, Li ZY (2014) Study on purification characteristic of $\mathrm{CO}_{2}$ and $\mathrm{CO}$ within closed environment of coal mine refuge chamber. Sep Purif Technol 130(10):65-73

Jia YX, Liu YS, Sun SF, Li HY, Jiao LL (2015) Refrigerating characteristics of ice storage capsule for temperature control of coal mine refuge chamber. Appl Therm Eng 75(22):756-762

Memon RA, Chirarattananon S, Vangtook P (2008) Thermal comfort assessment and application of radiant cooling: a case study. Build Environ 43(7):1185-1196

Muhi S, Butala V (2004) The influence of indoor environment in office buildings on their occupants, expected-unexpected. Build Environ 39(3):289-296

Noh KC, Jang JS, Oh MD (2007) Thermal comfort and indoor air quality in the lecture room with 4-way cassette air-conditioner and mixing ventilation system. Build Environ 42(2):689-698

Pourshaghaghy A, Omidvari M (2012) Examination of thermal comfort in a hospital using PMV-PPD model. Applied Ergon 43(6):1089-1095

Sabrina DC, Francesco M, Antonio S (2012) A measurement procedure to assess indoor environment quality for hypermarket workers. Build Environ 47:288-299

Mors S, Hensen JL, Loomans MG, Boerstra AC (2011) Adaptive thermal comfort in primary school classrooms: creating and validating PMV-based comfort charts. Build Environ 46(12):2454-2461

Yang JL, Yang LW, Wei J, Ma YZ, Zhang ZT (2013) Study on open cycle carbon dioxide refrigerator for movable mine refuge chamber. Appl Therm Eng 52(2):304-312 
Zhao HJ, Qian XM (2012) Simulation analysis on structure safety of two typical refuge chamber shell forms under explosion load. Procedia Eng 45:910-915
Zhao HJ, Qian XM, Li J (2012) Simulation analysis on structure safety of coal mine mobile refuge chamber under explosion load. Saf Sci 50(4):674-678 